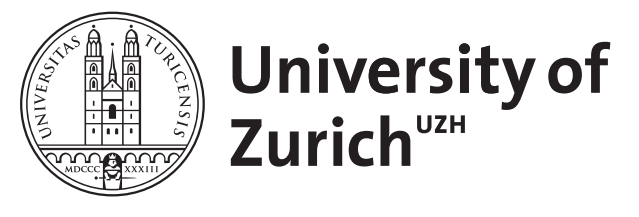

\title{
The photoreceptor cilium and its diseases
}

Bachmann-Gagescu, Ruxandra ; Neuhauss, Stephan C F

\begin{abstract}
Light sensation occurs in photoreceptor outer segments (OS), which derive from highly specialized primary cilia, based on structural and molecular similarities. Ciliary dysfunction causes ciliopathies, in which retinal degeneration is common. The connecting cilium (CC) is the obligate passage for proteins moving between ciliary and cellular compartment, controlling the correct distribution of proteins on either side of its barrier. While new mechanisms for selective entry of ciliary proteins are being elucidated, active transport out of the OS is increasingly studied. We further discuss other recent advances in the field, such as a role for the CC in docking and fusion of incoming transport vesicles, a newly proposed subcompartmentalization into proximal and distal CC, and mechanisms of OS membrane dynamics paralleling ectosome formation in other cilia.
\end{abstract}

DOI: https://doi.org/10.1016/j.gde.2019.05.004

Posted at the Zurich Open Repository and Archive, University of Zurich ZORA URL: https://doi.org/10.5167/uzh-179356

Journal Article

Accepted Version

Originally published at:

Bachmann-Gagescu, Ruxandra; Neuhauss, Stephan C F (2019). The photoreceptor cilium and its diseases. Current Opinion in Genetics Development, 56:22-33.

DOI: https://doi.org/10.1016/j.gde.2019.05.004 


\section{The photoreceptor cilium and its diseases}

Ruxandra Bachmann-Gagescu ${ }^{1,2}$ and Stephan C.F. Neuhauss ${ }^{2}$

1 Institute of Medical Genetics, University of Zurich, Wagistrasse 12, 8952 Schlieren, Zurich, Switzerland

2 Institute of Molecular Life Sciences, University of Zurich, Winterthurerstrassse 190, 8057 Zurich, Switzerland

ruxandra.bachmann@imls.uzh.ch

stephan.neuhauss@imls.uzh.ch

Corresponding author:

Ruxandra Bachmann-Gagescu

Institute of Medical Genetics

University of Zurich

Wagistrasse 12

8952 Schlieren, Zurich

Switzerland

+41799326905

ruxandra.bachmann@imls.uzh.ch 


\section{Abstract}

Light sensation occurs in photoreceptor outer segments (OS), which derive from highly specialized primary cilia, based on structural and molecular similarities. Ciliary dysfunction causes ciliopathies, in which retinal degeneration is common. The connecting cilium (CC) is the obligate passage for proteins moving between ciliary and cellular compartment, controlling the correct distribution of proteins on either side of its barrier. While new mechanisms for selective entry of ciliary proteins are being elucidated, active transport out of the OS is increasingly studied. We further discuss other recent advances in the field, such as a role for the $\mathrm{CC}$ in docking and fusion of incoming transport vesicles, a newly proposed sub-compartmentalization into proximal and distal CC, and mechanisms of OS membrane dynamics paralleling ectosome formation in other cilia.

Key words: Photoreceptors; outer segments; connecting cilium; trafficking; retinal ciliopathies. 


\section{Introduction: photoreceptor outer segments are specialized ciliary compartments}

Retinal photoreceptors (PR) are highly specialized neurons that have exquisitely adapted to their light-sensing function. To provide sufficient membrane surface to accommodate the components of the phototransduction cascade, which transforms incoming photons into electrical signal, they have evolved a unique cellular compartment called the outer segment (OS) consisting of stacked membrane discs (Figure 1) [1]. These are organized around a microtubule-based backbone called axoneme, which is anchored inside the inner segment (IS) of the cell body through a connecting cilium. OSs thus derive from highly specialized primary cilia, which are ubiquitous sensory organelles protruding from the surface of most differentiated vertebrate cell types [2].

PR OSs are in tight contact with retinal pigment epithelial (RPE) cells, which participate in the visual cycle by recycling retinol and which phagocytose old membrane discs from the apical OSs. Indeed, OSs are trimmed at the apex and regenerate from their base, with a daily $\sim 10 \%$ renewal rate [3]. In many species, the OS-base is also encased by actin-rich calyceal processes which extend from the IS [4]. The IS contains large numbers of mitochondria to meet the high energy demand of these metabolically very active cells. Given that OS, like all cilia, lack bio-synthetic machinery, all organelles involved in protein synthesis are located in the IS. This organization implies highly regulated sorting and trafficking of large amounts of proteins from their site of synthesis in the IS towards their site of action in the OS. The CC is an obligate passage point on this route, implying highly active trafficking through this compartment and making it the ideal control center for access to the OS.

An ever-increasing number of genes have been associated with inherited retinal degeneration (IRD), which can be congenital but is more frequently progressive, as partially dysfunctional PRs degenerate over time in response to cellular stress caused by structural defects, intracellular accumulation of abnormal proteins and/or secondary to light toxicity [5]. Disease genes encode phototransduction cascade components or structural OS proteins, whose dysfunction results in 
non-syndromic IRD, but also mitochondrial, synaptic or ciliary proteins. The latter cause so-called ciliopathies, a group of human disorders caused by dysfunction of primary cilia [6].

Primary cilia are microtubule-based organelles required for signal transduction [7]. All cilia harbor distinct subcompartments, predominantly: the basal body (BB), the connecting cilium (CC) in PRs which is the equivalent of the transition zone (TZ) in other cell types, the axoneme and the ciliary membrane. The BB is anchored inside the cell through the ciliary rootlet. The ciliary membrane's protein and lipid content are distinct from those of the surrounding plasma membrane, despite them being continuous with each other. Movement of proteins within the cilium relies on intraflagellar transport: IFT-B complex and kinesin motor for anterograde movement towards ciliary tip and IFT-A and dynein motor for retrograde movement back towards cell body [8]. An octameric protein complex called the BBSome acts as a coat adaptor for IFT-B and participates in controlling movement towards and within the cilium [9].

Ciliopathies are often multi-systemic disorders, in which retinal disease is but one symptom in a more complex constellation [10]. Examples include Bardet-Biedl syndrome (BBS), (OMIM 209900), in which retinal dystrophy is a hallmark of the disease, or Joubert syndrome (JS) (OMIM 213300 ), in which $\sim 25-30 \%$ of patients display retinal involvement [11]. In addition, mutations in ciliary genes represent the most common group of non-syndromic IRD. Interestingly, mutations in the same gene may result in isolated or in syndromic IRD. This is best illustrated by CEP290, which causes the non-syndromic IRD Leber congenital amaurosis (LCA), but also syndromic ciliopathies including JS or BBS $[11,12]$. Even mutations in the classical JS gene CC2D2A have now been described in non-syndromic cone-rod dystrophy [13]. The interested reader is referred to recently published comprehensive reviews on retinal ciliopathies [14-16]. The aim of the current short review is to discuss selected open questions in the field of PR cilium biology, focusing on the role of the $\mathrm{CC}$ as a crucial cellular hub, to summarize recent progress in our 
understanding of the pathomechanisms underlying retinal ciliopathies and to highlight promising model systems and therapeutic approaches for IRD.

\section{Current understanding of photoreceptor biology}

\section{The road to the outer segment - trafficking towards the cilium}

The high renewal rate of OSs involves extremely active trafficking of massive protein amounts towards the OS as well as complex sorting mechanisms. Trafficking of the light sensing protein Rhodopsin (a G-protein coupled receptor (GPCR) consisting of a covalently bound retinal to an opsin protein) has been thoroughly studied, as it represents the most abundant transmembrane OS protein. Much of our current understanding of the transport mechanisms of transmembrane OS proteins is therefore based on insights from Rhodopsin trafficking. Rhodopsin follows a canonical polarized exocytosis pathway, where cytoplasmic dynein moves opsin-carrier vesicles (OCVs) from Golgi to periciliary region [17]. Small Rab GTPases provide membrane identity for targeting to the appropriate membrane domain and interact with down-stream effectors for vesicle docking and fusion [18]. Deretic and colleagues showed in frog PRs that OCVs budding off the Golgi are coated by RAB11-ARF4-ASAP1-FIP3 and subsequently by RAB8 towards the ciliary base [19]. Rab GTPases act as molecular switches and Rab11 is known to activate Rabin8, which in turn activates Rab8. Overexpression of a dominant negative form of Rab8 led to PR degeneration in frogs [20]. In addition to their role in Rhodopsin trafficking in PRs, Rab8 and Rab11 also play a role in early ciliogenesis and in ciliary membrane biogenesis in hTERT-RPE1 cells [21]. However, a recent mouse study has questioned the role of Rab8 in ciliogenesis and Rhodopsin trafficking, since Rab8a knockouts lacked any retinal phenotype, despite additional expression of dominant negative forms of Rab8b, Rab11a/b and Rab10 [22]. This unexpected finding suggests either species differences between mouse and frog or indicates very high 
redundancy between Rabs. Our recent work in zebrafish supports a role for Rab8 in Rhodopsin trafficking: We confirmed the presence of Rab8 at the surface of OCVs using correlative light and electron microscopy and observed Rab8-positive particles moving along with Rhodopsin in the IS region with live imaging (Figure 2) [23].

\section{The connecting cilium- at the crossroads between inner and outer segment}

Once OCVs have reached the periciliary membrane, they must dock and fuse to deliver their cargo, which must then cross the barrier constituted by the connecting cilium (CC) in order to reach the OS membrane. While the role of the TZ/CC as a gatekeeper preventing mixing of ciliary with plasma membrane proteins is well established, the molecular mechanism by which this is achieved remains partly unsolved, in particular in PRs [24]. Two models can be proposed: The selective entry model, whereby only ciliary proteins can enter the ciliary compartment, versus the retention model, implying that only ciliary proteins are retained inside the compartment. Our recent work in zebrafish supports the selective entry model by identifying a role for the TZ/CC protein CC2D2A in docking of incoming OCVs through a chain of protein interactions between CC2D2A and the centrosomal protein NINL, which in turn binds the cytoplasmic dynein complex implicated in carrying OCVs to the periciliary region [25]. In parallel, NINL also binds MICAL3, a previously identified interactor and effector of Rab8. Finally, loss of the TZ/CC protein CC2D2A also results in loss of vesicle fusion components from the periciliary membrane such as t-SNAREs SNAP25 and Syntaxin3 $[23,26,27]$, explaining the observed massive accumulation of unfused vesicles in cc2d2a-/- zebrafish PRs.

Passage through the barrier constituted by the CC is the next challenge on the road to the OS. Many ciliopathy proteins such as CEP290 localize to the TZ/CC, associating into multi-protein complexes including the MKS-module (CC2D2A-MKS1,3-TCTNs-TMEMs-B9D1,2) or the NPHP module (RPGRIP-RPGRIP1L-NPHP1-NPHP4) [28]. Joining ciliary membrane and microtubules are the Y-links. How do transmembrane proteins pass through the Y-links of the TZ/CC? An 
interesting recent study identified the formation of ternary complexes between the ciliary targeting signal (CTS) of Rhodopsin, Rab8 and Transportin1 (TNPO1), allowing selective passage of the diffusion barrier at the base of the cilium [29]. Intriguingly, this study also showed leakiness of the diffusion barrier whereby non-ciliary proteins can enter the ciliary compartment by lateral diffusion. In this model, selective transport of ciliary-resident proteins is however strongly enhanced by presence of the CTS and its association with Importins. In addition, a long-standing model suggests that Rhodopsin is being dragged through the $\mathrm{CC}$ barrier by active transport relying on IFT, as it is a known IFT-cargo [30]. An interesting recent study identified a PR-specific subcompartmentalization of the CC: While the basal CC is proposed to represent the equivalent of the TZ in other cilia, IRD-associated protein SPATA7, which is known to interact with RPGRIP and RPGR, was shown to define a distal CC compartment specific to PRs [31,32].

Recent work on BBS proteins suggests that active transport out of the cilium to remove proteins from the ciliary compartment is also important in controlling the ciliary protein content [33]. Earlier work proposed that the BBSome- a multiprotein complex composed of BBS-associated proteinsacts as a coat targeting incoming OCVs to the OS, based on intracellular Rhodopsin accumulation in BBSome mutants [34]. Newer results suggest an alternative model: Deficient transport of nonOS proteins out of the OS in the absence of a functional BBSome is now proposed to underlie the retinal degeneration of mouse Bbs17/Lztf1 and Bbs8 knockouts. This is based on early OS enrichment of Syntaxin3, normally a plasma membrane protein, before Rhodopsin mislocalization and PR degeneration occur [35-37]. In fact, the OS has been suggested to act as a "sink" for membrane proteins [38], supporting the retention model: non-ciliary proteins, which have (accidentally) entered the cilium, are actively transported out. Active retrograde transport from ciliary compartment to cell body in PRs is somewhat unexpected, in light of the unique apical shedding of OSs and the consequent one-way direction of proteins trafficking into the OS required for disc renewal. This begs the question which OS components would require regulated active 
transport back into the cell body under physiological conditions. Tubulin and IFT components are obvious candidates, but other proteins may undergo similar turnover. Further investigation of retrograde transport in PRs is warranted, also in light of the retinal phenotypes observed in mutants with deficient retrograde IFT [39]. Additionally, OSs may participate in other signaling pathways beyond light sensation, which could rely on retrograde transport, a yet unexplored possibility. Of note, the light-dependent bi-directional movement into and out of the OS of phototransduction cascade components which are not transmembrane proteins (Transducin or Recoverin) proceeds by diffusion, and is therefore outside of the scope of this discussion. Likewise, the transport of membrane-associated (but not transmembrane) proteins such as INPPE relies on chaperonines like PDE6D and is not addressed in this discussion which focuses on trafficking of OS transmembrane proteins.

\section{Inside the OS: membrane disc formation and maintenance}

Once Rhodopsin has passed the CC, it is incorporated into the OS membrane from where it must reach the nascent OS discs. In fact, Rhodopsin trafficking is tightly coupled with OS membrane genesis and disc stacking, since the density of Rhodopsin in OS membranes is such that Rhodopsin also plays a structural role in these membrane stacks [40]. The debate over the mechanism underlying new disc formation, opposing a hypothesized endocytic pathway to the OS membrane evagination model, has been largely settled in favor of the latter by recent electron microscopy studies [41]. Actin is enriched at the site of neo-disc formation and plays an important role in OS evagination [42]. An intriguing new study describes a tendency for PRs to produce ectosomes, a process also relying on Actin in other cilia types [43]. Ectosome release from other primary cilia has been reported by several groups, with various proposed purposes including intercellular signaling or removal of excess ciliary proteins [44]. Salinas et al. now propose a role for Peripherin in inhibiting the release of ectosomes from PR cilia, so that these can be reshaped into flattened membrane discs [45]. This function for Peripherin is independent of its role in 
bending the membranes at the disc edges [46]. In agreement, recent work from another group supports a role for oligomerized Peripherin (Prph2)-Rom1 in initiation and maturation of OSs [47].

Disc formation at the OS base implies that newer discs push older discs apically, where they are eventually shed and engulfed by the RPE. This apical shedding can also be paralleled with ectosome release from the ciliary tip. Once Rhodopsin has reached the OS, it is incorporated into membrane discs and does not require IFT for transport, as it moves along with the discs. Besides tubulin, which is required to maintain the axoneme-backbone of the OS, it remains unclear which cargo is shuttled by IFT inside OSs. As in other cilia, the membrane-associated Joubert proteins ARL13B and INPP5E are found in the OS. The phosphatase INPP5E controls the phosphoinositide composition of the ciliary membrane in other cilia, thereby controlling hedgehog signaling [48]. Its precise function in OSs has not been determined but its interaction with the PRspecific RPGR and PDE6ठ suggests it may control phosphoinositide composition of the OS membrane as well [49]. The small GTPase ARL13B is responsible for localizing INPP5E inside the cilium but also for releasing cargo such as ARL3 from its transporter [50-52]. Interestingly, ARL13B was recently shown to be required for constructing the TZ/CC in PRs, possibly through an interaction with IFT components $[53,54]$. Thanks to modern proteomic techniques, many more OS proteins not involved in phototransduction will likely be identified in the near future, as has been the case for other ciliary compartments [55].

\section{When the PR cilium is sick: pathomechanisms underlying retinal ciliopathies}

Ciliopathy proteins localize at any of the different ciliary subcompartments (BB-TZ/CCaxoneme/cilium), indicating that they play different roles in ciliary function and consequently cause

retinal disease by different mechanisms. Schematically, these can be subdivided into primarily ciliogenesis defects versus primarily trafficking defects of signaling proteins. Since BB proteins 
are frequently involved in the early steps of ciliogenesis [56], their dysfunction commonly leads to ciliogenesis defects and therefore lack of OSs in PRs, as illustrated by the zebrafish talpid3/kiaa0586 mutant [5]. TALPID3 interacts with MACF1, which coordinates Actin and microtubules and whose absence leads to similar PR phenotypes, illustrating the importance of environing non-bona fide ciliary constituent proteins for ciliogenesis [57]. MACF1 mutations leading to decreased cilium length were recently identified in patients with complex brain malformations [58] and this gene is thus a good candidate for causing IRD. However, complete absence of cilia is likely lethal and ciliogenesis defects in patients can only be partial, leading to progressive PR cell death in the retina. Dysfunction of BB proteins cause a variety of ciliopathies including JS but also non-syndromic IRD. Likewise, deficient IFT results generally in ciliogenesis defects given its role in transporting the tubulin building blocks of the axoneme, even though signaling proteins are also affected secondarily. Interestingly, individuals carrying mutations in IFT genes present predominantly with skeletal dysplasia, often with perinatal mortality. Retinal disease is present in a subset of those affected with milder forms. Dysfunction of TZ proteins, as seen in JS and its related disorders, or of BBSome proteins in BBS, leads to mislocalization or loss of signaling proteins such as GPCRs from the cilium, with secondary deficits in signaling which are identical to those resulting from mutations in genes encoding these ciliary proteins. As an example, mutations in TZ-protein encoding genes or in INPP5E lead to loss of INPP5E protein from the cilium and result in JS. Similarly, mutations in genes encoding CC components such as RPGR result in similar loss of Rhodopsin from the OS and therefore similar patient phenotypes as observed with $R H O$ mutations. Finally, closely associated with the cilium, mutations in genes active at the actin-rich calyceal processes or the periciliary region cause Usher syndrome, a disorder also affecting the actin-based stereocilia in the inner ear and resulting in blindness and deafness [59]. For a summary of selected ciliopathies with retinal involvement, associated genes and presumed function of encoded proteins see Table 1. An updated list of IRD genes is found on retnet (https://sph.uth.edu/retnet/home.htm). 
Prominent phenotypic variability in ciliopathies makes it difficult to predict the severity or occurrence of retinal disease in a given patient. The causal mutations are likely the strongest determinant of clinical outcome, but human genetics studies have identified only few genotypephenotype correlations. In vitro modeling now allows to move forward: using patient fibroblasts and derived iPSC-optic cups, Shimada et al showed how LCA-associated mutations had weaker effects on cilium structure and function than JS-associated mutations [60]. In addition to mutationspecific outcomes, intra-familial variability suggests additional influences of environment or genetic background. While "genetic modifiers" most likely exist, their identification based on human genetics alone remains challenging [61], given the rarity of these diseases and their prominent genetic heterogeneity.

\section{Novel developments: retinal disease models and therapeutic approaches}

Since retinal architecture and PR structure are exceptionally well conserved among vertebrates, many animal models have contributed to our current understanding of PR physiology and disease. Each model has its strengths and weaknesses: while mice represent the most commonly used animal model for IRD, they do lack a cone-rich macula or calyceal processes. On the other hand, the study of cats, dogs and primates poses more challenging ethical and practical problems. Lower vertebrates offer specific advantages, beyond their practicality and lower costs; Frogs have very large OSs, making them ideal for biochemical studies, while zebrafish offer excellent conditions for live imaging of transgenically-tagged proteins of interest in PRs in a whole tissue context or for chemical screens to identify new therapies. Recent technological breakthroughs offer exciting prospects for disease-relevant in vitro modeling including human retinal explants or iPSC-derived eye cups [62]. Current limitations include short survival of retinal explants or, for retinal organoids, the difficulty to generate OSs that are ultra-structurally comparable to PRs in vivo, but future technological developments are likely to bring further improvements. 
As our understanding of PR biology, disease genes and mechanisms increases, several therapeutic approaches are reaching the clinic. Gene replacement therapy for LCA caused by RPE65 mutations has been FDA-approved and represents one of the very first successes in classical gene therapy [63]. It remains to be proven that similar success can be obtained with replacement of large genes encoding structural proteins such as CEP290 or other TZ/CC components, rather than with a small enzyme like RPE65. Indeed, the capacity of employed AAV vectors represents but one limitation of this approach. In the particular case of CEP290, the sizeissue might be overcome, based on recently published rescue in a Cep290 KO mouse model with the C-terminal portion of the protein [64]. In contrast, the large size of ciliary genes may not be a problem for in vivo gene editing. The limitation here lies in delivery and above all in the editing efficiency. Encouraging results have been published for in vivo correction in a rat model for Mertklinked RP [65] and in human retinal explants, mouse and primate models for the common deep intronic CEP290 allele c.2991+1655A>G (IVS26) allele [66]. Another mutation-specific approach relies on administration of antisense oligonucleotides for mutations affecting splicing. First successes in patients carrying the common CEP290 IVS26 allele have just been published [67]. Relying on novel culture technologies, the possibility of retinal cell transplant therapies is being actively explored [68]. These experiments have also identified previously unrecognized exchange of cytoplasmic material between PRs [69]. Finally, treatments that are not mutation-specific hold the promise of being more affordable. Examples include read-through drugs for nonsense mutations [70], manipulation of the U1 splicing factor for mutations affecting splicing [71] or neuroprotective/neurotrophic factors [72].

\section{Conclusion}

We have reached a good understanding of PR biology, highlighting the importance of the cilium as a crucial hub in these highly specialized neurons. The progressive nature of IRD provides a 
time-window for treatment. As novel therapeutic approaches are on the horizon, it becomes essential to determine the genetic cause in each patient and to understand the underlying pathomechanisms, in order to propose the most appropriate treatment. Our limited prognostic ability for individual patients remains a major drawback, which should be addressed by combined approaches allying human genetics with functional modeling in the exciting new model systems that are being developed. 


\section{Acknowledgements}

We apologize to researchers whose work relevant to this review we could not cite due to space constraints. We would like to dedicate this review to Jarema Malicki, who made significant contributions to our understanding of PR biology. RBG and SCFN are supported by Swiss SNF grants P00P3_170681 and 31003A_173083, respectively.

The authors declare no conflict of interest 
Table 1: Ciliopathies with retinal involvement

\begin{tabular}{|c|c|c|c|c|c|c|c|c|}
\hline Ciliopathy & $\begin{array}{l}\text { Retinal } \\
\text { disease }\end{array}$ & \begin{tabular}{|l|} 
Other \\
phenotypes
\end{tabular} & $\begin{array}{l}\text { BBSome and } \\
\text { associated/ } \\
\text { chaperonin } \\
\text { proteins } \\
\rightarrow \text { Trafficking } \\
\text { in/out of } \\
\text { OS/cilium } \\
\end{array}$ & $\begin{array}{l}\text { BB proteins } \\
\Rightarrow \quad \text { Ciliogenesis } \\
\text { (+docking of } \\
\text { incoming carrier } \\
\text { vesicles?) }\end{array}$ & $\begin{array}{l}\text { TZ/CC proteins } \\
\rightarrow \quad \text { Gatekeeper of } \\
\text { ciliary/OS } \\
\text { compartment } \\
\text { (+docking/sorting } \\
\text { of incoming carrier } \\
\text { vesicles?) }\end{array}$ & $\begin{array}{l}\text { Ciliary proteins } \\
\rightarrow \text { Signaling }\end{array}$ & $\begin{array}{l}\text { IFT proteins and motors } \\
\rightarrow \quad \text { Movement across } \\
\text { TZ/CC and along } \\
\text { axoneme }\end{array}$ & Other/multiple \\
\hline \multicolumn{9}{|c|}{ Syndromic ciliopathies } \\
\hline $\begin{array}{l}\text { Bardet-Biedl } \\
\text { (BBS) } \\
N=\sim 21 \text { genes }\end{array}$ & $\begin{array}{l}\text { Cone-rod } \\
\text { dystrophy }\end{array}$ & \begin{tabular}{|l|} 
fibro-cystic renal \\
disease, \\
developmental \\
delay/intellectual \\
disability, \\
polydactyly, obesity \\
and hypogonadism \\
\end{tabular} & $\begin{array}{l}\text { BBS1-BBS1 } \\
\text { BBS2 - BBS2 } \\
\text { ARL } 6 \text { - BBS3 } \\
\text { BBS4 - BBS4 } \\
\text { BBS5 - BBS5 } \\
\text { MKKS - BBS6 } \\
\text { BBS7- BBS7 } \\
\text { TTC8 - BBS8 } \\
\text { BBS9 - BBS9 } \\
\text { BBS10-BBS10 } \\
\text { BBS12- BBS12 } \\
\text { LZTFL } 1 \text { - BBS17 } \\
\text { BBIP1-BBS18 }\end{array}$ & \begin{tabular}{|l} 
? WDPCP - BBS15 \\
SDCCA8 - BBS16 \\
C8orf37 - BBS21
\end{tabular} & \begin{tabular}{|l|} 
MKS1 - BBS13 \\
CEP290 - BBS14
\end{tabular} & & $\begin{array}{l}\text { IFT27 - BBS19 (R) } \\
\text { FT172 - BBS20 (A) }\end{array}$ & ? TRIM32-BBS11 \\
\hline $\begin{array}{l}\text { Alstrøm } \\
N=1 \text { gene }\end{array}$ & $\begin{array}{l}\text { Cone-rod } \\
\text { dystrophy }\end{array}$ & \begin{tabular}{|l} 
deafness, obesity, \\
diabetes mellitus, \\
\pm cardiomyopathy, \\
\pm hepatitis \\
\pm nephritis \\
\end{tabular} & & ALMS1 & & & & \\
\hline
\end{tabular}




\begin{tabular}{|c|c|c|c|c|c|c|c|c|}
\hline $\begin{array}{l}\text { Meckel (MKS) } \\
N=\sim 13 \text { genes }\end{array}$ & $\begin{array}{l} \pm \text { micro- } \\
\text { phtalmia, } \\
\text { coloboma }\end{array}$ & $\begin{array}{l}\text { Polydactyly } \\
\text { Cystic kidneys } \\
\text { Liver fibrosis } \\
\text { Encephalocele }\end{array}$ & & KIF14 - MKS12 & $\begin{array}{l}\text { MKS1 - MKS1 } \\
\text { TMEM216 - MKS2 } \\
\text { TMEM67 - MKS3 } \\
\text { CEP290 - MKS4 } \\
\text { RPGRIP1L - MKS5 } \\
\text { CC2D2A - MKS6 } \\
\text { NPHP3 - MKS7 } \\
\text { TCTN2 - MKS8 } \\
\text { B9D1 - MKS9 } \\
\text { B9D2 - MKS10 } \\
\text { TMEM231 - MKS11 } \\
\text { TMEM107 - MKS13 }\end{array}$ & & & \\
\hline $\begin{array}{l}\text { Senior-Løken } \\
N=\sim 8 \text { genes }\end{array}$ & $\begin{array}{l}\text { Cone-rod } \\
\text { dystrophy }\end{array}$ & Nephronophthisis & & $\begin{array}{l}\text { IQCB1 - SLSN5 } \\
\text { SDCCAG8 - SLSN6 }\end{array}$ & $\begin{array}{l}\text { NPHP1 - SLSN1 } \\
\text { NPHP3 - SLSN3 } \\
\text { NPHP4 - SLSN4 } \\
\text { CEP290 - SLSN6 }\end{array}$ & & $\begin{array}{l}\text { WDR19/IFT144 - SLSN8 (R) } \\
\text { TRAF3IP1/IFT54 - SLSN9 (A) }\end{array}$ & \\
\hline $\begin{array}{l}\text { Skeletal } \\
\text { ciliopathies: } \\
N=\sim 19 \text { genes } \\
\text { Short Rib } \\
\text { Polydactyly } \\
\text { group (SRP) } \\
\text { - SRP I-IV } \\
\text { - Jeune ATD }\end{array}$ & $\begin{array}{l} \pm \mathrm{LCA}-\mathrm{RP} \text { in } \\
\text { survivors }\end{array}$ & $\begin{array}{l}\text { Skeletal } \\
\text { abnormalities with } \\
\text { constricted thoracic } \\
\text { cage, short ribs and } \\
\text { shortened tubular } \\
\text { bones } \\
\text { Polydactyly } \\
\pm \text { Nephronophtisis }\end{array}$ & & $\begin{array}{l}\text { NEK1 - SRTD6 } \\
\text { CEP120 - SRTD13 } \\
\text { KIAA0586 - SRTD15 } \\
\text { ? INTU - SRTD20 }\end{array}$ & & & $\begin{array}{l}\text { IFT80 - SRTD2 (A) } \\
\text { DYNC2H1 - SRTD3 (R) } \\
\text { TTC21B - SRTD4 (R) } \\
\text { WDR19 - SRTD5 (R) } \\
\text { WDR35 - SRTD7 (R) } \\
\text { WDR60 - SRTD8 (R) } \\
\text { IFT140 - SRTD9 (R) } \\
\text { IFT172 - SRTD10 (A) } \\
\text { WDR34 - SRTD11(R) } \\
\text { DYNC2LI1 - SRTD14 } \\
\text { IFT52 - SRTD16 (A) } \\
\text { TCTEX1D2 - SRTD17 (R) } \\
\text { IFT43 - SRTD18 (R) } \\
\text { IFT81 - SRTD19 (A) }\end{array}$ & \\
\hline $\begin{array}{l}\text { Usher } \\
N=\sim 9 \text { genes }\end{array}$ & $\mathrm{RP}$ & $\begin{array}{l}\text { Sensorineural } \\
\text { deafness }\end{array}$ & & $\begin{array}{l}\text { USH2A - USH2A } \\
\text { WHRN - USH2D } \\
\text { USH1G - USH1G }\end{array}$ & $\begin{array}{l}\text { CDH23 - USH1D } \\
P C D H 15 \text { - USH1F } \\
\text { ADGRV1/GPR98 - } \\
\text { USH2C }\end{array}$ & & & $\begin{array}{l}\text { MYO7A - USH1B } \\
\text { USH1C/PDZD7 - } \\
\text { USH1C } \\
\text { CIB2 - USH1J }\end{array}$ \\
\hline \multicolumn{9}{|c|}{ Non-syndromic retinal ciliopathies (selected cilia-related proteins) } \\
\hline $\begin{array}{l}\text { Leber } \\
\text { congenital } \\
\text { amaurosis }\end{array}$ & $\begin{array}{l}\text { Congenital } \\
\text { blindness }\end{array}$ & None (Isolated IRD) & & $\begin{array}{l}\text { LCA5- LCA5 } \\
\text { IQCB1 }\end{array}$ & $\begin{array}{l}\text { RPGRIP1- LCA6 } \\
\text { CEP290 - LCA10 }\end{array}$ & $\begin{array}{l}\text { SPATA7- LCA3 } \\
\text { PRPH2 - LCA18 }\end{array}$ & $\begin{array}{l}\text { CLUAP1 (A) } \\
\text { IFT140 (R) }\end{array}$ & TULP1-LCA15 \\
\hline $\begin{array}{l}\text { Cone rod } \\
\text { dystrophy }\end{array}$ & $\begin{array}{l}\text { Cone > rod } \\
\text { degeneration } \\
\left(1^{\text {st }} \text { visual }\right. \\
\text { acuity })\end{array}$ & None (Isolated IRD) & & & $\begin{array}{l}R P G R \text { - CORD1 } \\
\text { RPGRIP - CORD13 }\end{array}$ & & & \\
\hline $\begin{array}{l}\text { Retinitis } \\
\text { pigmentosa }\end{array}$ & $\begin{array}{l}\text { Rod> cone } \\
\text { degeneration } \\
\text { (1st night } \\
\text { blindness) }\end{array}$ & None (Isolated IRD) & $\begin{array}{l}\text { ARL6 - RP55 } \\
\text { BBS2 - RP74 }\end{array}$ & $\begin{array}{l}\text { RP2 - RP2 (XLR) } \\
\text { OFD1- RP23 (XLR) } \\
\text { FAM161A - RP28 } \\
\text { (AR) } \\
\text { USH2A - RP39 (AR) }\end{array}$ & $\begin{array}{l}\text { RP1 - RP1 (AR/AD) } \\
R P G R-\mathrm{RP3}\end{array}$ & $\begin{array}{l}\text { RHO - RP4 (AD) } \\
\text { PRPH2 - RP7 } \\
\text { (AD) } \\
\text { PCARE/ C2orf71 - } \\
\text { RP54 (AR) } \\
\text { SPATA7 (AR) }\end{array}$ & $\begin{array}{l}\text { IFT172 - RP71 (A), (AR) } \\
\text { IFT140 - RP80 (A), (AR) } \\
\text { IFT43 - RP81 (R), (AR) }\end{array}$ & $\begin{array}{l}\text { TULP1 - RP14 (AR) } \\
\text { ARL3 - RP83 (AD) }\end{array}$ \\
\hline
\end{tabular}


For each clinical disorder (left column), associated genes (italicized gene name - locus name) are sorted by the main localization and presumed function of the encoded protein. Question marks indicate genes with limited evidence for the particular disease association (i.e. single family). Note that for clarity, only one localization/function is shown, even though for some proteins several have been proposed. The main phenotypes in the retina and in other systems are described for each disorder; \pm indicates variable presence of this feature. Note for the syndromic ciliopathies, how each disorder is predominantly caused by dysfunction of proteins from one particular ciliary

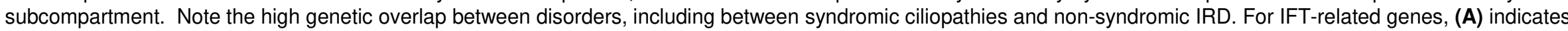
anterograde IFT and (R) retrograde IFT. For non-syndromic retinal ciliopathies, only a small subset of associated genes are displayed, with focus on cilia-related proteins,

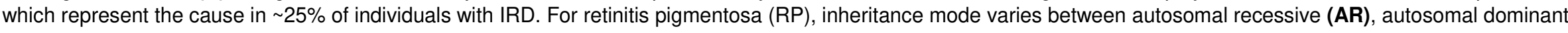
(AD) and X-linked (XL). In all other ciliopathies, inheritance is generally recessive. For a comprehensive updated list, please refer to retnet

(https://sph.uth.edu/retnet/home.htm). ATD Asphyxiating Thoracic Dystophy, BB Basal Body, IFT Intra Flagellar Transport, IRD Inherited retinal degeneration, LCA Leber Congenital Amaurosis, OS Outer Segment, RP retinitis pigmentosa, TZ/CC Transition Zone/Connecting Cilium. 

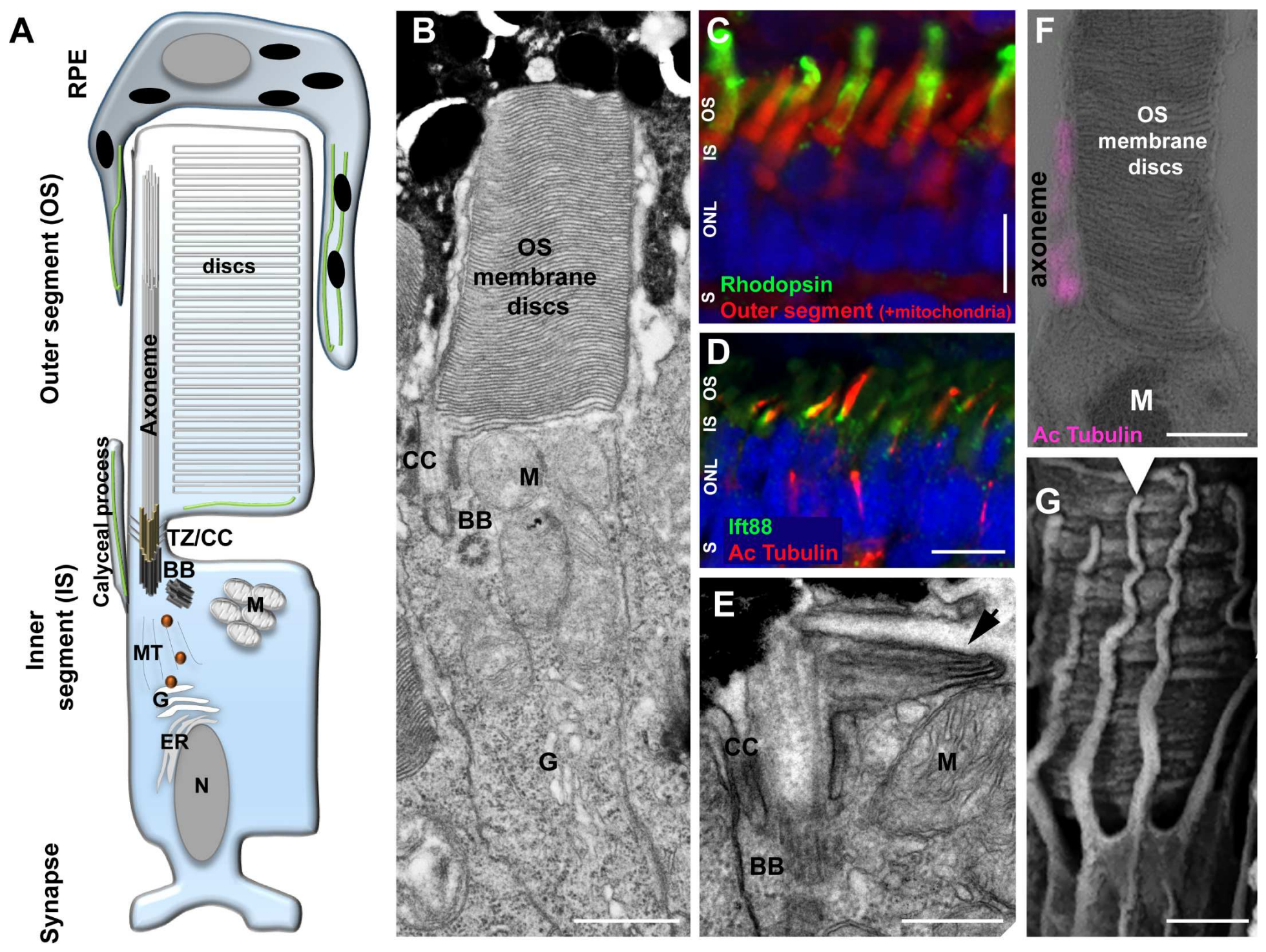

Figure 1: Photoreceptor morphology and ultrastructure: the Outer Segment is a specialized ciliary compartment. 
(A) Schematic of a PR cell. Note the organization into synaptic region at the base, inner segment and apical outer segment. The latter is composed of membrane discs, the axoneme forming the axis. Note how the base of the OS is encased by the calyceal processes while their apical region is in close contact with the RPE cell. Actin in the calyceal processes, the RPE cell extensions and at the base of the cilium is schematized in green. Red spheres represent ciliary-directed vesicles. (B) Transmission electron micrograph (TEM) of a larval zebrafish PR showing the same structures as described in the schematic in (A). (C) Immunofluorescence (IF) of larval zebrafish retina, where the lipophilic dye Bodipy (red) highlights the OS (and mitochondrial cluster), and anti-Rhodopsin (4D2) antibody (green) marks the subset of PRs expressing this particular opsin subtype. Nuclei are counterstained with DAPI. (D) IF of larval zebrafish retina with anti-Ift88, coating the basal axoneme and anti-Acetylated Tubulin highlighting the entire axoneme. (E) TEM image of early larval zebrafish PR showing initial stacking of membrane discs (arrow) at the onset of OS development. This image is modified from Ojeda Naharros et al., Sci Reports [5]. (F) Correlative light and electron microscopy (CLEM) image of a larval zebrafish PR where antiAcetylated Tubulin (magenta) signal overlays the SEM image of the OS/IS region. (G) Scanning electron microscopy image of an adult zebrafish PR highlighting the calyceal processes (arrowhead). Scale bars: $1 \mu \mathrm{m}$ in (B), $4 \mu \mathrm{m}$ in (C-D), $0.5 \mu \mathrm{m}$ in (E), $1 \mu \mathrm{m}$ in (F-G). Ac Tubulin Acetylated Tubulin, BB basal Body, ER endoplasmic reticulum, G Golgi apparatus, IS inner segment, M Mitochondria, MT Microtubules, N Nucleus, ONL Outer nuclear layer, OS Outer segment, RPE retinal pigment epithelium cell, S synapse, TZ/CC Transition Zone/ Connecting Cilium. 

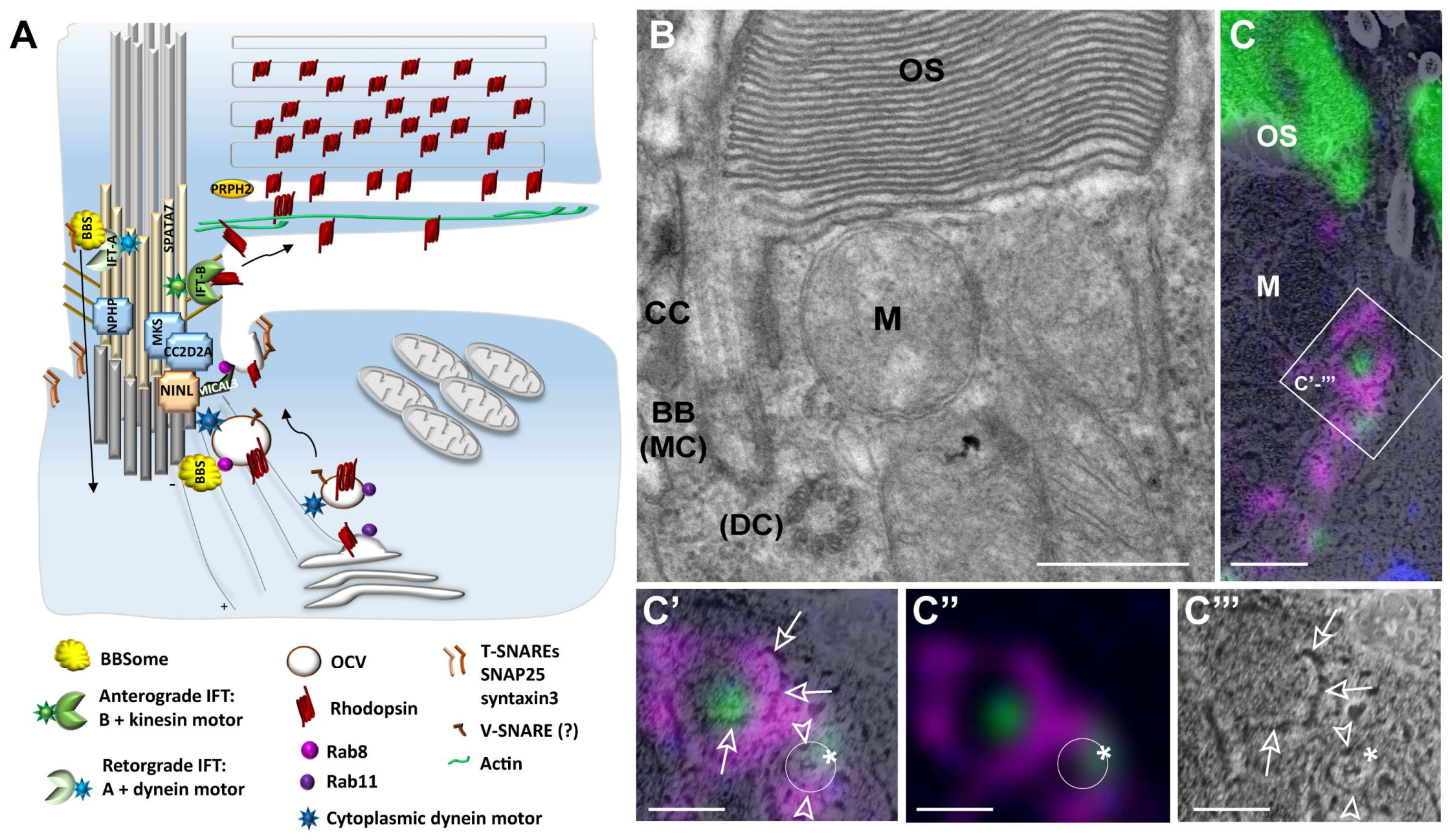

Figure 2: Trafficking around the base of the OS: the $\mathrm{CC}$ as a central hub. 
(A) Simplified schematic of the IS/OS junction around the CC: opsin-carrier vesicles (OCVs) bud off the Golgi coated with Rab11 (purple sphere) and move along microtubules using cytoplasmic dynein-1 motor (dark blue star) towards the BB which acts as microtubule-organizing center. Arriving in the vicinity of the cilium, Rab8 (pink sphere) is now found at the OCV surface. OCVs then dock at the ciliary base, thanks to interaction of the dynein motor with the centrosomal protein NINL, which in turn binds CC2D2A at the TZ/CC. Fusion of OCVs with the periciliary membrane is mediated by interaction of v-SNARE with t-SNAREs (light and dark brown lines) and by interaction of Rab8 with MICAL3 (which also binds NINL). An interaction between Rab8 and the BBSome (yellow cloud) may also play a role. Transport of Rhodopsin after OCV fusion is mediated by its interaction with IFT-B trains (dark green pacman) moving thanks to the kinesin motor (green star). New discs are born through evagination of the OS membrane for which Actin (green lines) and Peripherin2 (PRPH2 orange) play an important role. Movement of proteins form OS back to IS (Syntaxin 3, brown line) is mediated by the BBSome interacting with IFT-A trains (light green pacman) that move using dynein-2 motor (light blue star). The MKS and NPHP complexes are in the proximal CC while the distal CC is organized by SPATA7. Several structures such as the rootlet or daughter centriole have been omitted for clarity. (B) TEM image of larval zebrafish PR focusing on the IS/OS junction. (C) CLEM image of transgenic larval zebrafish expressing mCherry-tagged Rab8a (magenta) in rod PRs, co-stained with anti-Rhodopsin antibody (4D2, green). (C'-C'”) are higher magnification of the boxed area in $(C)$, showing the merged image (C'), the IF image only (C"') and the SEM image only (C'”). Note in C"' the small vesicle (arrowheads just above and just below); the asterisk marks the location of the Rhodopsin signal (see C"). Arrows point to a multi-lobulated structure likely resulting from aggregates of vesicles. Note the presence of Rhodopsin in both types of vesicular structures, identifying them as OCVs, and the presence of mCherry-Rab8a on their surface. Scale bars: 0.5 $\mu \mathrm{m}$ in (B) and (C'-C'”), $1 \mu \mathrm{m}$ in (C). Panels (C-C'”) are modified from Ojeda Naharros et al., PLoS Genet. [23]. CC Connecting Cilium, 
BB basal Body, MC Mother Centriole, DC Daughter Centriole, OS Outer segment, N Nucleus, M Mitochondria, OCV opsin carrier vesicle, IFT intra-flagellar transport. 


\section{BOX1: Outstanding questions and outlook}

Photoreceptor Biology: Work from many groups has elucidated sequential aspects of Rhodopsin trafficking, cilium formation or OS disc stacking, but an integrated view linking all these events and the hand-over between different steps have yet to be fully elucidated. A selection of open questions includes:

1. How can the apparent dispensability and redundancy of Rab GTPases be reconciled with the canonical view stipulating that they provide membrane identity for vesicular trafficking?

2. How do incoming transmembrane proteins pass through the $\mathrm{Y}$-links of the $\mathrm{CC}$ ? Is there an interaction between TZ/CC proteins and BBSome or IFT?

3. How leaky is the diffusion barrier and what is the balance between selective entry vs retention of ciliary proteins? How important is the newly identified retrieval role of BBSome components for ciliary exit of non-ciliary proteins in OSs?

4. In light of the predominant direction of transport towards the OS for disc renewal, what is the role of retrograde transport out of the cilium and which components are normally brought back into the cell?

5. Do PR cilia have a signaling function beyond opsin-dependent light sensation, which would involve regulated transport from OS towards IS?

Clinical aspects of inherited retinal degeneration: A major challenge remains the prediction of outcome in a given patient, due to the prominent phenotypic variability observed in ciliopathies. As efficient treatments come into view, this limitation will become critical, as we will need to determine which patient to treat how and when. Truly personalized medicine, with mutation- or gene-specific treatments such as gene replacement therapy, gene editing or antisense oligonucleotides, is now on the horizon, but is hampered by practical considerations linked to the rarity of each genetic cause. Finding economically viable solutions making these treatments affordable will represent a major challenge. In parallel, drug-based treatments applicable to a variety of genetic causes should be further explored for combinatorial treatment approaches. 


\section{References}

1. Kolb H. Webvision: The Organization of the Retina and Visual System: Photoreceptors; 2005.

2. Kennedy B, Malicki J: What drives cell morphogenesis: A look inside the vertebrate photoreceptor. Dev. Dyn. 2009;238(9):2115-38, doi:10.1002/dvdy.22010.

3. Young RW: THE RENEWAL OF PHOTORECEPTOR CELL OUTER SEGMENTS. The Journal of Cell Biology 1967;33(1):61, doi:10.1083/jcb.33.1.61.

4. Schietroma C, Parain K, Estivalet A, Aghaie A, Boutet de Monvel J, Picaud S, Sahel J-A, Perron M, ElAmraoui $A$, Petit $C$ : Usher syndrome type 1-associated cadherins shape the photoreceptor outer segment. The Journal of Cell Biology 2017;216(6):1849, doi:10.1083/jcb.201612030.

5. Naharros IO, Cristian FB, Zang J, Gesemann M, Ingham PW, Neuhauss SCF, Bachmann-Gagescu R: The ciliopathy protein TALPID3/KIAA0586 acts upstream of Rab8 activation in zebrafish photoreceptor outer segment formation and maintenance. Sci. Rep. 2018;8(1):2211, doi:10.1038/s41598-018-20489-9.

6. Badano JL, Mitsuma N, Beales PL, Katsanis N: The Ciliopathies: An Emerging Class of Human Genetic Disorders. Annu. Rev. Genom. Human Genet. 2006;7(1):125-48, doi:10.1146/annurev.genom.7.080505.115610.

7. Goetz SC, Anderson KV: The primary cilium: a signalling centre during vertebrate development. Nat Rev Genet 2010;11(5):331-44, doi:10.1038/nrg2774.

8. Rosenbaum JL, Cole DG, Diener DR: Intraflagellar Transport: The Eyes Have It. The Journal of Cell Biology 1999;144(3):385, doi:10.1083/jcb.144.3.385.

9. Nachury MV, Loktev AV, Zhang Q, Westlake CJ, Peränen J, Merdes A, Slusarski DC, Scheller RH, Bazan JF, Sheffield VC et al.: A Core Complex of BBS Proteins Cooperates with the GTPase Rab8 to Promote Ciliary Membrane Biogenesis. Cell 2007;129(6):1201-13, doi:10.1016/j.cell.2007.03.053.

10. Hildebrandt F, Benzing T, Katsanis N: Ciliopathies. N Engl J Med 2011;364(16):1533-43, doi:10.1056/NEJMra1010172.

11. Bachmann-Gagescu R, Dempsey JC, Phelps IG, O'Roak BJ, Knutzen DM, Rue TC, Ishak GE, Isabella CR, Gorden N, Adkins J et al.: Joubert syndrome: a model for untangling recessive disorders with extreme genetic heterogeneity. Journal of Medical Genetics 2015(52(8)):514-22, doi:10.1136/jmedgenet-2015-103087.

12. Coppieters F, Lefever S, Leroy BP, Baere E de: CEP290, a gene with many faces: mutation overview and presentation of CEP290base. Hum. Mutat. 2010;31(10):1097-108, doi:10.1002/humu.21337.

13. Méjécase C, Hummel A, Mohand-Saïd S, Andrieu C, El Shamieh S, Antonio A, Condroyer C, Boyard F, Foussard $\mathrm{M}$, Blanchard $\mathrm{S}$ et al.: Whole exome sequencing resolves complex phenotype and identifies CC2D2A mutations underlying non-syndromic rod-cone dystrophy. Clin Genet 2019;95(2):329-33, doi:10.1111/cge.13453. 
14. May-Simera H, Nagel-Wolfrum K, Wolfrum U: Cilia - The sensory antennae in the eye. Progress in Retinal and Eye Research 2017;60:144-80, doi:10.1016/j.preteyeres.2017.05.001.

15. Baehr W, Hanke-Gogokhia C, Sharif A, Reed M, Dahl T, Frederick JM, Ying G: Insights into photoreceptor ciliogenesis revealed by animal models. Progress in Retinal and Eye Research 2018, doi:10.1016/j.preteyeres.2018.12.004.

16. Bujakowska KM, Liu Q, Pierce EA: Photoreceptor Cilia and Retinal Ciliopathies. Cold Spring Harbor Perspectives in Biology 2017;9(10), doi:10.1101/cshperspect.a028274.

17. Papermaster DS, Schneider BG, Besharse JC: Vesicular transport of newly synthesized opsin from the Golgi apparatus toward the rod outer segment. Ultrastructural immunocytochemical and autoradiographic evidence in Xenopus retinas. Invest. Ophthalmol. Vis. Sci. 1985;26(10):1386-404.

18. T1 - Rab GTPases in cilium formation and function AU - Blacque, Oliver E., Scheidel N, Kuhns S: Rab GTPases in cilium formation and function AU - Blacque, Oliver E. Small GTPases 2018;9(1-2):76-94, doi:10.1080/21541248.2017.1353847.

19. Wang J, Morita Y, Mazelova J, Deretic D: The Arf GAP ASAP1 provides a platform to regulate Arf4and Rab11-Rab8-mediated ciliary receptor targeting. The EMBO Journal 2012;31(20):4057-71, doi:10.1038/emboj.2012.253.

20. Deretic D, Huber LA, Ransom N, Mancini M, Simons K, Papermaster DS: Rab8 in retinal photoreceptors may participate in rhodopsin transport and in rod outer segment disk morphogenesis. Journal of Cell Science 1995;108:215-24.

21. Westlake CJ, Baye LM, Nachury MV, Wright KJ, Ervin KE, Phu L, Chalouni C, Beck JS, Kirkpatrick DS, Slusarski DC et al.: Primary cilia membrane assembly is initiated by Rab11 and transport protein particle II (TRAPPII) complex-dependent trafficking of Rabin8 to the centrosome. Proceedings of the National Academy of Sciences 2011;108(7):2759-64, doi:10.1073/pnas.1018823108.

22. Ying G, Gerstner CD, Frederick JM, Boye SL, Hauswirth WW, Baehr W: Small GTPases Rab8a and Rab11a Are Dispensable for Rhodopsin Transport in Mouse Photoreceptors. PloS one 2016;11(8):e0161236, doi:10.1371/journal.pone.0161236.

23. Ojeda Naharros I, Gesemann M, Mateos JM, Barmettler G, Forbes A, Ziegler U, Neuhauss SCF, Bachmann-Gagescu R: Loss-of-function of the ciliopathy protein Cc2d2a disorganizes the vesicle fusion machinery at the periciliary membrane and indirectly affects Rab8-trafficking in zebrafish photoreceptors. PLoS Genet. 2017;13(12):e1007150, doi:10.1371/journal.pgen.1007150.

24. Reiter JF, Blacque OE, Leroux MR: The base of the cilium: roles for transition fibres and the transition zone in ciliary formation, maintenance and compartmentalization. $E M B O$ reports 2012;13(7):608-18, doi:10.1038/embor.2012.73.

25. Bachmann-Gagescu R, Dona M, Hetterschijt L, Tonnaer E, Peters T, Vrieze E de, Mans DA, van Beersum SEC, Phelps IG, Arts HH et al.: The Ciliopathy Protein CC2D2A Associates with NINL and Functions in RAB8-MICAL3-Regulated Vesicle Trafficking. PLoS Genet. 2015;11(10):e1005575, doi:10.1371/journal.pgen.1005575. 
26. Mazelova J, Ransom N, Astuto-Gribble L, Wilson MC, Deretic D: Syntaxin 3 and SNAP-25 pairing, regulated by omega-3 docosahexaenoic acid, controls the delivery of rhodopsin for the biogenesis of cilia-derived sensory organelles, the rod outer segments. Journal of Cell Science 2009;122(12):2003, doi:10.1242/jcs.039982.

27. Kandachar V, Tam BM, Moritz OL, Deretic D: An interaction network between the SNARE VAMP7 and Rab GTPases within a ciliary membrane-targeting complex. Journal of Cell Science 2018;131(24):jcs222034, doi:10.1242/jcs.222034.

28. Sang L, Miller JJ, Corbit KC, Giles RH, Brauer MJ, Otto EA, Baye LM, Wen X, Scales SJ, Kwong M et al.: Mapping the NPHP-JBTS-MKS Protein Network Reveals Ciliopathy Disease Genes and Pathways. Cell 2011;145(4):513-28, doi:10.1016/j.cell.2011.04.019.

29. Madugula V, Lu L: A ternary complex comprising transportin1, Rab8 and the ciliary targeting signal directs proteins to ciliary membranes. Journal of Cell Science 2016;129(20):3922, doi:10.1242/jcs.194019.

30. Bhowmick R, Li M, Sun J, Baker SA, Insinna C, Besharse JC: Photoreceptor IFT Complexes Containing Chaperones, Guanylyl Cyclase 1 and Rhodopsin. Traffic 2009;10(6):648-63, doi:10.1111/j.16000854.2009.00896.x.

31. Eblimit A, Nguyen T-MT, Chen Y, Esteve-Rudd J, Zhong H, Letteboer S, van Reeuwijk J, Simons DL, Ding $Q$, Wu KM et al.: Spata7 is a retinal ciliopathy gene critical for correct RPGRIP1 localization and protein trafficking in the retina. Human Molecular Genetics 2015;24(6):1584-601, doi:10.1093/hmg/ddu573.

32. Dharmat R, Eblimit A, Robichaux MA, Zhang Z, Nguyen T-MT, Jung SY, He F, Jain A, Li Y, Qin J et al.: SPATA7 maintains a novel photoreceptor-specific zone in the distal connecting cilium. The Journal of Cell Biology 2018;217(8):2851, doi:10.1083/jcb.201712117.

33. Liew GM, Ye F, Nager AR, Murphy JP, Lee JS, Aguiar M, Breslow DK, Gygi SP, Nachury MV: The Intraflagellar Transport Protein IFT27 Promotes BBSome Exit from Cilia through the GTPase ARL6/BBS3. Developmental Cell 2014;31(3):265-78, doi:10.1016/j.devcel.2014.09.004.

34. Nishimura DY, Fath M, Mullins RF, Searby C, Andrews M, Davis R, Andorf JL, Mykytyn K, Swiderski RE, Yang $B$ et al.: Bbs2-null mice have neurosensory deficits, a defect in social dominance, and retinopathy associated with mislocalization of rhodopsin. Proceedings of the National Academy of Sciences of the United States of America 2004;101(47):16588-93, doi:10.1073/pnas.0405496101.

35. Datta P, Allamargot C, Hudson JS, Andersen EK, Bhattarai S, Drack AV, Sheffield VC, Seo S: Accumulation of non-outer segment proteins in the outer segment underlies photoreceptor degeneration in Bardet-Biedl syndrome. Proceedings of the National Academy of Sciences 2015;112(32):E4400, doi:10.1073/pnas.1510111112.

36. Saravanan T, Moye A, Singh RK, Dilan TL, Ramamurthy V, Stoilov P, Goldberg AFX: Bardet-Biedl syndrome-8 (BBS8) protein is crucial for the development of outer segments in photoreceptor neurons. hmg 2017;27(2):283-94, doi:10.1093/hmg/ddx399. 
37. Hsu Y, Garrison JE, Kim G, Schmitz AR, Searby CC, Zhang Q, Datta P, Nishimura DY, Seo S, Sheffield VC: BBSome function is required for both the morphogenesis and maintenance of the photoreceptor outer segment. PLoS Genet 2017;13(10):e1007057, doi:10.1371/journal.pgen.1007057.

38. Datta P, Seo S: Photoreceptor outer segment as a sink for membrane proteins: hypothesis and implications in retinal ciliopathies. $h m g$ 2017;26(R1):R75-R82, doi:10.1093/hmg/ddx163.

39. Boubakri M, Chaya T, Hirata H, Kajimura N, Kuwahara R, Ueno A, Malicki J, Furukawa T, Omori Y: Loss of ift122, a Retrograde Intraflagellar Transport (IFT) Complex Component, Leads to Slow, Progressive Photoreceptor Degeneration Due to Inefficient Opsin Transport. Journal of Biological Chemistry 2016;291(47):24465-74, doi:10.1074/jbc.M116.738658.

40. Goldberg AFX, Moritz OL, Williams DS: Molecular basis for photoreceptor outer segment architecture. Progress in Retinal and Eye Research 2016;55:52-81, doi:10.1016/j.preteyeres.2016.05.003.

41. Ding J-D, Salinas RY, Arshavsky VY: Discs of mammalian rod photoreceptors form through the membrane evagination mechanism. The Journal of Cell Biology 2015;211(3):495, doi:10.1083/jcb.201508093.

42. Chaitin MH, Schneider BG, Hall MO, Papermaster DS: Actin in the photoreceptor connecting cilium: immunocytochemical localization to the site of outer segment disk formation. The Journal of Cell Biology 1984;99(1):239, doi:10.1083/jcb.99.1.239.

43. Nager AR, Goldstein JS, Herranz-Pérez V, Portran D, Ye F, Garcia-Verdugo JM, Nachury MV: An Actin Network Dispatches Ciliary GPCRs into Extracellular Vesicles to Modulate Signaling. Cell 2017;168(1):252-263.e14, doi:10.1016/j.cell.2016.11.036.

44. Phua SC, Chiba S, Suzuki M, Su E, Roberson EC, Pusapati GV, Setou M, Rohatgi R, Reiter JF, Ikegami K et al.: Dynamic Remodeling of Membrane Composition Drives Cell Cycle through Primary Cilia Excision. Cell 2017;168(1):264-279.e15, doi:10.1016/j.cell.2016.12.032.

45. Salinas RY, Pearring JN, Ding J-D, Spencer WJ, Hao Y, Arshavsky VY: Photoreceptor discs form through peripherin-dependent suppression of ciliary ectosome release. The Journal of Cell Biology 2017;216(5):1489, doi:10.1083/jcb.201608081.

46. Stuck MW, Conley SM, Naash MI: PRPH2/RDS and ROM-1: Historical context, current views and future considerations. Progress in Retinal and Eye Research 2016;52:47-63, doi:10.1016/j.preteyeres.2015.12.002.

47. Watson JN, Burnett JL, Stuck MW, Conley SM, Zulliger R, Naash MI: Prph2 initiates outer segment morphogenesis but maturation requires Prph2/Rom1 oligomerization. hmg 2018;28(3):459-75, doi:10.1093/hmg/ddy359.

48. Garcia-Gonzalo FR, Phua SC, Roberson EC, Garcia G, Abedin M, Schurmans S, Inoue T, Reiter JF: Phosphoinositides Regulate Ciliary Protein Trafficking to Modulate Hedgehog Signaling. Developmental Cell 2015;34(4):400-9, doi:10.1016/j.devcel.2015.08.001. 
49. Rao KN, Li L, Anand M, Zhang W, Khanna H: Prenylated retinal ciliopathy protein RPGR interacts with PDE6 $\delta$ and regulates ciliary localization of Joubert syndrome-associated protein INPP5E. $\mathrm{hmg}$ 2016;25(20):4533-45, doi:10.1093/hmg/ddw281.

50. Humbert MC, Weihbrecht K, Searby CC, Li Y, Pope RM, Sheffield VC, Seo S: ARL13B, PDE6D, and CEP164 form a functional network for INPP5E ciliary targeting. Proceedings of the National Academy of Sciences of the United States of America 2012;109(48):19691-6, doi:10.1073/pnas.1210916109.

51. Gotthardt K, Lokaj M, Koerner C, Falk N, GießI A, Wittinghofer A, Clapham DE: A G-protein activation cascade from Arl13B to Arl3 and implications for ciliary targeting of lipidated proteins. eL ife 2015;4:e11859, doi:10.7554/eLife.11859.

52. Hanke-Gogokhia C, Wu Z, Gerstner CD, Frederick JM, Zhang H, Baehr W: Arf-like Protein 3 (ARL3) Regulates Protein Trafficking and Ciliogenesis in Mouse Photoreceptors. Journal of Biological Chemistry 2016;291(13):7142-55, doi:10.1074/jbc.M115.710954.

53. Hanke-Gogokhia C, Wu Z, Sharif A, Yazigi H, Frederick JM, Baehr W: The guanine nucleotide exchange factor Arf-like protein $13 \mathrm{~b}$ is essential for assembly of the mouse photoreceptor transition zone and outer segment. Journal of Biological Chemistry 2017;292(52):21442-56, doi:10.1074/jbc.RA117.000141.

54. Nozaki S, Katoh Y, Terada M, Michisaka S, Funabashi T, Takahashi S, Kontani K, Nakayama K: Regulation of ciliary retrograde protein trafficking by the Joubert syndrome proteins ARL13B and INPP5E. Journal of Cell Science 2017;130(3):563, doi:10.1242/jcs.197004.

55. Boldt K, van Reeuwijk J, Lu Q, Koutroumpas K, Nguyen T-MT, Texier Y, van Beersum SEC, Horn N, Willer JR, Mans DA et al.: An organelle-specific protein landscape identifies novel diseases and molecular mechanisms. Nature Communications 2016;7:11491 EP -, doi:10.1038/ncomms11491.

56. Santos N, Reiter JF: Building it up and taking it down: The regulation of vertebrate ciliogenesis. Developmental dynamics an official publication of the American Association of Anatomists 2008;237(8):1972-81, doi:10.1002/dvdy.21540.

57. May-Simera HL, Gumerson JD, Gao C, Campos M, Cologna SM, Beyer T, Boldt K, Kaya KD, Patel N, Kretschmer F et al.: Loss of MACF1 Abolishes Ciliogenesis and Disrupts Apicobasal Polarity Establishment in the Retina. Cell reports 2016;17(5):1399-413, doi:10.1016/j.celrep.2016.09.089.

58. Dobyns WB, Aldinger KA, Ishak GE, Mirzaa GM, Timms AE, Grout ME, Dremmen MHG, Schot R, Vandervore L, van Slegtenhorst MA et al.: MACF1 Mutations Encoding Highly Conserved ZincBinding Residues of the GAR Domain Cause Defects in Neuronal Migration and Axon Guidance. The American Journal of Human Genetics 2018;103(6):1009-21, doi:10.1016/j.ajhg.2018.10.019.

59. Samanta A, Knapp B, Plutniok J, Bauß K, Nagel-Wolfrum K, Sorusch N, Wolfrum U: Characterization of the ternary Usher syndrome SANS/ush2a/whirlin protein complex. hmg 2017;26(6):1157-72, doi:10.1093/hmg/ddx027.

60. Shimada H, Lu Q, Insinna-Kettenhofen C, Nagashima K, English MA, Semler EM, Mahgerefteh J, Cideciyan AV, Li T, Brooks BP et al.: In Vitro Modeling Using Ciliopathy-Patient-Derived Cells 
Reveals Distinct Cilia Dysfunctions Caused by CEP290 Mutations. Cell reports 2017;20(2):384-96, doi:10.1016/j.celrep.2017.06.045.

61. Phelps IG, Dempsey JC, Grout ME, Isabella CR, Tully HM, Doherty D, Bachmann-Gagescu R: Interpreting the clinical significance of combined variants in multiple recessive disease genes. Systematic investigation of Joubert syndrome yields little support for oligogenicity. Genetics In Medicine 2017;20:223 EP -, doi:10.1038/gim.2017.94.

62. Gonzalez-Cordero A, Kruczek K, Naeem A, Fernando M, Kloc M, Ribeiro J, Goh D, Duran Y, Blackford $\mathrm{SJ}$, Abelleira-Hervas L et al.: Recapitulation of Human Retinal Development from Human Pluripotent Stem Cells Generates Transplantable Populations of Cone Photoreceptors. Stem Cell Reports 2017;9(3):820-37, doi:10.1016/j.stemcr.2017.07.022.

63. Russell S, Bennett J, Wellman JA, Chung DC, Yu Z-F, Tillman A, Wittes J, Pappas J, Elci O, McCague S et al.: Efficacy and safety of voretigene neparvovec (AAV2-hRPE65v2) in patients with RPE65mediated inherited retinal dystrophy: a randomised, controlled, open-label, phase 3 trial. The Lancet 2017;390(10097):849-60, doi:10.1016/S0140-6736(17)31868-8.

64. Mookherjee S, Chen HY, Isgrig K, Yu W, Hiriyanna S, Levron R, Li T, Colosi P, Chien W, Swaroop A et al.: A CEP290 C-Terminal Domain Complements the Mutant CEP290 of Rd16 Mice In Trans and Rescues Retinal Degeneration. Cell reports 2018;25(3):611-623.e6, doi:10.1016/j.celrep.2018.09.043.

65. Suzuki K, Tsunekawa Y, Hernandez-Benitez R, Wu J, Zhu J, Kim EJ, Hatanaka F, Yamamoto M, Araoka $\mathrm{T}$, Li $Z$ et al.: In vivo genome editing via CRISPR/Cas9 mediated homology-independent targeted integration. Nature 2016;540:144 EP -, doi:10.1038/nature20565.

66. Maeder ML, Stefanidakis M, Wilson CJ, Baral R, Barrera LA, Bounoutas GS, Bumcrot D, Chao H, Ciulla $\mathrm{DM}$, DaSilva JA et al.: Development of a gene-editing approach to restore vision loss in Leber congenital amaurosis type 10. Nature Medicine 2019, doi:10.1038/s41591-018-0327-9.

67. Cideciyan AV, Jacobson SG, Drack AV, Ho AC, Charng J, Garafalo AV, Roman AJ, Sumaroka A, Han IC, Hochstedler MD et al.: Effect of an intravitreal antisense oligonucleotide on vision in Leber congenital amaurosis due to a photoreceptor cilium defect. Nature Medicine 2018, doi:10.1038/s41591-018-0295-0.

68. Singh R, Cuzzani O, Binette F, Sternberg H, West MD, Nasonkin IO: Pluripotent Stem Cells for Retinal Tissue Engineering: Current Status and Future Prospects. Stem Cell Reviews and Reports 2018;14(4):463-83, doi:10.1007/s12015-018-9802-4.

69. Waldron PV, Di Marco F, Kruczek K, Ribeiro J, Graca AB, Hippert C, Aghaizu ND, Kalargyrou AA, Barber AC, Grimaldi G et al.: Transplanted Donor- or Stem Cell-Derived Cone Photoreceptors Can Both Integrate and Undergo Material Transfer in an Environment-Dependent Manner. Stem Cell Reports 2018;10(2):406-21, doi:10.1016/j.stemcr.2017.12.008.

70. Nagel-Wolfrum K, Möller F, Penner I, Wolfrum U: Translational read-through as an alternative approach for ocular gene therapy of retinal dystrophies caused by in-frame nonsense mutations. Visual Neuroscience 2014;31(Special Issue 4-5):309-16, doi:10.1017/S0952523814000194. 
71. Schmid F, Hiller T, Korner G, Glaus E, Berger W, Neidhardt J: A Gene Therapeutic Approach to Correct Splice Defects with Modified U1 and U6 snRNPs. Human Gene Therapy 2012;24(1):97-104, doi:10.1089/hum.2012.110.

72. Mockel A, Obringer C, Hakvoort TBM, Seeliger M, Lamers WH, Stoetzel C, Dollfus H, Marion V: Pharmacological Modulation of the Retinal Unfolded Protein Response in Bardet-Biedl Syndrome Reduces Apoptosis and Preserves Light Detection Ability. Journal of Biological Chemistry 2012;287(44):37483-94, doi:10.1074/jbc.M112.386821. 


\section{Selected literature annotations}

* May-Simera H, Nagel-Wolfrum K, Wolfrum U: Cilia - The sensory antennae in the eye. Progress in Retinal and Eye Research 2017;60:144-80, doi:10.1016/j.preteyeres.2017.05.001

This is a comprehensive review on the role of cilia in the eye, including PRs but also additional cell types.

** Ojeda Naharros I, Gesemann M, Mateos JM, Barmettler G, Forbes A, Ziegler U, Neuhauss SCF, Bachmann-Gagescu R: Loss-of-function of the ciliopathy protein Cc2d2a disorganizes the vesicle fusion machinery at the periciliary membrane and indirectly affects Rab8-trafficking in zebrafish photoreceptors. PLoS Genet. 2017;13(12):e1007150, doi:10.1371/journal.pgen.1007150.

In this study, we show that Rab8 does coat opsin-carrier vesicles using correlative light and electron microscopy (CLEM). Moreover, we prove using live imaging in zebrafish retina that Rab8-particles and Rhodopsin move together in the IS of PRs. We also identify a role for the $T Z / C C$ protein CC2D2A in fusion of OCVs by controlling the organization of SNAREs and Syntaxin in the periciliary membrane.

** Madugula V, Lu L: A ternary complex comprising transportin1, Rab8 and the ciliary targeting signal directs proteins to ciliary membranes. Journal of Cell Science 2016;129(20):3922, doi:10.1242/jcs.194019

In this study, the authors observe that the ciliary membrane diffusion barrier is leaky and that plasma membrane proteins can enter ciliary membranes non-selectively. However, they show that proteins with importin-binding motifs have increased ciliary localization and that the ciliarytargeting signal of Rhodopsin forms a complex with Rab8 and TNPO1. They further suggest that such complexes selectively facilitate the crossing of ciliary residents through the diffusion barrier.

* Hsu Y, Garrison JE, Kim G, Schmitz AR, Searby CC, Zhang Q, Datta P, Nishimura DY, Seo S, Sheffield VC: BBSome function is required for both the morphogenesis and maintenance of the photoreceptor outer segment. PLoS Genet 2017;13(10):e1007057

The authors confirm the intra-OS accumulation of Syntaxin-3 in Bbs8-/- PRs, supporting a role for Bbs8 in transporting proteins out of the OS. Using a reversible Bbs8 knockout system, they further show that rescue is possible even in PRs with already malformed OSs, which are progressively replaced by normally formed OS discs. This finding supports the relevance of gene therapy, at least in partially immature retina.

** Salinas RY, Pearring JN, Ding J-D, Spencer WJ, Hao Y, Arshavsky VY: Photoreceptor discs form through peripherin-dependent suppression of ciliary ectosome release. The Journal of Cell Biology 2017;216(5):1489, doi:10.1083/jcb.201608081.

Studying a Periperin KO mouse (Rds-/-), the authors describe a spontaneous tendency for ectosome formation in PRs, similar to what has been described in other cilia. The formation of 
ectosomes is however inhibited in PRs by Periperin (independently of its previously known function in controlling membrane disc bending at the disc edges). In the absence of Peripherin, they observe accumulation of subretinal vesicles.

\section{** Shimada H, Lu Q, Insinna-Kettenhofen C, Nagashima K, English MA, Semler EM, Mahgerefteh J, Cideciyan AV, Li T, Brooks BP et al.: In Vitro Modeling Using Ciliopathy- Patient-Derived Cells Reveals Distinct Cilia Dysfunctions Caused by CEP290 Mutations. Cell reports 2017;20(2):384-96, doi:10.1016/j.celrep.2017.06.045}

Relying on fibroblasts derived from patients with CEP290-associated LCA or JS, the authors identify distinct effects on ciliogenesis: LCA-mutations cause milder defects as JS-mutations, providing functional evidence for a genotype-phenotype correlation. In addition, the authors demonstrate that PRs in iPSC-derived eye cups from a LCA-patient have more severe ciliogenesis defects than fibroblasts from that same patient, indicating cell-type specific effects of given CEP290 mutations.

\footnotetext{
** Maeder ML, Stefanidakis M, Wilson CJ, Baral R, Barrera LA, Bounoutas GS, Bumcrot D, Chao H, Ciulla DM, DaSilva JA et al.: Development of a gene-editing approach to restore vision loss in Leber congenital amaurosis type 10. Nature Medicine 2019, doi:10.1038/s41591-018-0327-9.
}

In this study, the authors developed a gene-editing approach to remove the aberrant splice site from the common CEP290 IVS26 allele. Very encouraging editing efficiency is reported not only in vitro in human retinal explants but also in mouse and non-human primates in vivo, supporting the applicability of this therapeutic approach in patients.

** Cideciyan AV, Jacobson SG, Drack AV, Ho AC, Charng J, Garafalo AV, Roman AJ, Sumaroka A, Han IC, Hochstedler MD et al.: Effect of an intravitreal antisense oligonucleotide on vision in Leber congenital amaurosis due to a photoreceptor cilium defect. Nature Medicine 2018, doi:10.1038/s41591-018-0295-0

The authors report preliminary results from a trial using antisense oligonucleotides on patients with the common CEP290 (IVS26) mutation that results in aberrant splicing. While these are very early results and the long-term efficiency must be further monitored, they report encouraging results. 